\title{
O ENSINO DE TEORIA DA CONTABILIDADE NO BRASIL APÓS O PROCESSO DE CONVERGÊNCIA DAS NORMAS INTERNACIONAIS DE CONTABILIDADE SOB A ÓTICA DOS DOCENTES DO ESTADO DO PARANÁ
}

\author{
Rodrigo Baraco Marassi 1 \\ Luiza Betânia Fasolin 2 \\ Roberto Carlos Klann 3
}

- Artigo recebido em: 06/12/2016 -• Artigo aceito em: 07/05/2018 -" Segunda versão aceita em: 29/07/2018

\section{RESUMO}

Este estudo buscou verificar as principais mudanças ocorridas no ensino da disciplina de Teoria da Contabilidade no Brasil após o processo de convergência das normas internacionais de contabilidade, com base na perspectiva dos docentes do Estado do Paraná. A pesquisa se classifica como descritiva, quantitativa, com levantamento dos dados por meio de um questionário enviado pelo Google Docs a 84 instituições de ensino superior do Estado do Paraná, que oferecem o curso de Ciências Contábeis. O questionário foi respondido por 30 docentes da disciplina de Teoria da Contabilidade dessas instituições, compondo assim, a amostra deste estudo. Os dados foram analisados por meio de estatística descritiva e posteriormente foi aplicado o grau de entropia da informação nos resultados. Os resultados demonstram que o processo de convergência às normas internacionais de contabilidade resultou em alterações no ensino da disciplina Teoria da Contabilidade. Os docentes tiveram que se readequar para transmitir o conteúdo dessa disciplina aos acadêmicos. Contatou-se que os respondentes concordam que alguns dos pronunciamentos estão sendo eficazes para aplicação do conteúdo. O teste da entropia demonstrou alta concordância dos docentes sobre a utilização deste instrumento nas aulas, mas sobre sua eficácia para aplicação do conteúdo aos alunos, a concordância foi menor. Pode-se concluir que o processo de convergência às normas internacionais de contabilidade causou alterações no ensino da disciplina de Teoria da Contabilidade, sob a ótica dos docentes do Estado do Paraná. Como sugestão para pesquisas futuras, seria interessante abranger outras disciplinas, o que poderia contribuir para a

\footnotetext{
1 Mestre em Ciências Contábeis pela Universidade Regional de Blumenau - FURB. Endereço: R. Antônio da Veiga, 140 - Itoupava Seca, Blumenau - SC, 89030-003. Fone: (47) 3321-0565. email: rodrigomarassi_16@hotmail.com.

2 Mestre em Ciências Contábeis pela Universidade Regional de Blumenau -FURB. Endereço: R. Antônio da Veiga, 140 - Itoupava Seca, Blumenau - SC, 89030-003. Fone: (47) 3321-0200. email: Ivisa_fasolin@hotmail.com.

3 Doutor em Ciências Contábeis e Administração pela Universidade Regional de Blumenau FURB. Coordenador e Professor do Programa de Pós-Graduação em Ciências Contábeis da Universidade Regional de Blumenau - FURB. Endereço: R. Antônio da Veiga, 140 - sala D202 Itoupava Seca, Blumenau - SC, 89030-003. Fone: (47) 3321-0565. e-mail: rklann@furb.br.
} 
O Ensino de Teoria da Contabilidade no Brasil após o processo de Convergência Contábil Internacional

compreensão dos efeitos da convergência nas normas internacionais de contabilidade na qualidade do ensino da contabilidade no Brasil.

Palavras-chave: Teoria da Contabilidade. Normas Internacionais de Contabilidade. Pronunciamentos Contábeis.

\title{
THE TEACHING OF ACCOUNTING THEORY IN BRAZIL AFTER THE PROCESS OF INTERNATIONAL ACCOUNTING CONVERGENCE
}

\begin{abstract}
This study aimed to verify the main changes that occurred in the teaching of Accounting Theory in Brazil after the process of convergence of international standards of international accounting, based on the perspective of the teachers of the State of Paraná. The research is classified as descriptive, quantitative, with data collection through a questionnaire sent by Google Docs to 84 institutions of higher education of the State of Paraná, which offer the course of Accounting Sciences. The questionnaire was answered by 30 professors of the discipline of Accounting Theory of these institutions, thus composing the sample of this study. The data were analyzed using descriptive statistics and the degree of entropy of the information was then applied to the results. The results show that the process of convergence to international accounting standards has resulted in changes in the teaching of Accounting Theory. The teachers had to readjust to transmit the content of this discipline to the academics. Respondents were contacted to agree that some of the pronouncements are being effective in applying the content. The entropy test showed high agreement among the teachers about the use of this instrument in the classes, but on its effectiveness for applying the content to the students, the agreement was less. It can be concluded that the process of convergence to the international accounting standards caused changes in the teaching of the discipline of Accounting Theory, from the perspective of the teachers of the State of Paraná. The Accounting Pronouncements Committee is being an important instrument for this readjustment. As a suggestion for future research, it would be interesting to cover other disciplines, which could contribute to the understanding of the effects of convergence on international standards of international accounting in the quality of accounting education in Brazil.
\end{abstract}

Keywords: Accounting Theory. International Accounting Standards. Accounting Pronouncements.

\section{INTRODUÇÃO}

A Contabilidade está sujeita às influências do ambiente em que atua, sendo suas práticas fortemente afetadas pelos valores culturais, estrutura política, econômica e social. Dessa forma, os sistemas contábeis se diferenciam de acordo com o conjunto de leis, filosofias, procedimentos e objetivos de cada país (NIYAMA, 2007). 
Novos desafios estão sendo trazidos para a contabilidade, causados pelas constantes mudanças no cenário econômico mundial, em que a economia globalizada, o desenvolvimento do mercado de capitais internacional e o aumento dos investimentos estrangeiros geram a necessidade de utilização de normas e procedimentos que contribuam para a redução das diferenças nas informações contábeis entre os países (BARBOSA; DIAS; PINHEIRO, 2009).

A convergência das normas contábeis se faz necessária na medida em que os negócios não estão mais restritos apenas aos limites de um país (SANTOS et al., 2010). A fim de minimizar as divergências internacionais e facilitar a comunicação e a comparação das informações contábeis, existe um consenso entre os diversos envolvidos para uma convergência dos procedimentos contábeis em âmbito mundial (NIYAMA, 2007).

Com o processo de convergência das normas internacionais de contabilidade surge a necessidade de um novo enquadramento das disciplinas nos cursos de Ciências Contábeis (ESPEJO et al., 2010), dentre as quais se encontra a de Teoria da Contabilidade. As entidades educacionais devem buscar se interar das necessidades atuais do mercado, adotando disciplinas voltadas à realidade, introduzindo metodologias de ensino mais eficazes (FAHL; MANHANI, 2006).

Essa disciplina desenvolve o senso crítico, estimula a relação entre os conhecimentos práticos e teóricos, diminui o pragmatismo e aproxima o aluno da ciência e da pesquisa (MADEIRA; MENDONÇA; ABREU, 2003). É de grande relevância para os profissionais e estudantes, pois serve de fundamento para soluções de problemas empíricos, como também para a interpretação de novas situações no decorrer do exercício da profissão (BORBA; POETA; VICENTE, $2011)$.

A Lei no. 11.638/07 promoveu diversas mudanças na Lei n. 6.404/76 (lei das Sociedades por Ações), dentre elas pode-se citar a definição de empresa de grande porte, operações relacionadas à combinação de negócios, reservas de reavaliação, ativos financeiros e imobilizados, ativos e passivos de longo prazo, investimento em coligada (ZELIOLI, 2009). Essas mudanças acabam impactando na disciplina de Teoria da Contabilidade, pois conforme menciona Espejo et al. (2010), houve alterações na estrutura, na mensuração, reconhecimento e divulgação das informações contábeis.

Diante deste contexto, a presente pesquisa questiona: Quais foram as mudanças ocorridas no ensino da disciplina de Teoria da Contabilidade após o processo de convergência das normas internacionais de contabilidade sob a ótica dos docentes? Assim, o objetivo do estudo é verificar as principais mudanças ocorridas no ensino da disciplina de Teoria da Contabilidade no Brasil, após o processo de convergência das normais internacionais de contabilidade, com base na perspectiva dos docentes do Estado do Paraná.

Quanto às justificativas para este estudo, diversas pesquisas foram desenvolvidas a respeito do ensino da contabilidade, as quais abordam a necessidade de conhecimentos científicos por parte dos professores desta disciplina (SACRAMENTO, 1998) e buscam entender como o ensino contribui 
para o domínio de conceitos relevantes sobre a Contabilidade (LIMA FILHO; BRUNI, 2012). Há também estudos que verificam como está sendo ministrada a disciplina de Teoria da Contabilidade nos cursos de graduação em Ciências Contábeis no Brasil (THEÓPHILO et al., 2000), nos cursos de graduação e pósgraduação nas universidades estrangeiras (FERREIRA et al., 2013) e nos programas de mestrado brasileiro, comparando com alguns programas dos EUA (BORBA; POETA; VICENTE, 2011).

A presente pesquisa difere dessas anteriores por analisar as principais modificações no conteúdo e na didática desta disciplina em função do processo de convergência das normas internacionais de contabilidade, a partir da visão dos profissionais que ensinam esta disciplina. Ding et al. (2007) e Elbannam (2011) sustentam que a qualidade da educação contábil pode explicar o sucesso do processo de convergência em um país. Assim, os resultados visam corroborar a literatura existente, no aspecto da importância desta disciplina no meio acadêmico, além de destacar as principais modificações nela implementadas a partir do processo de convergência contábil, o que pode ajudar a entender a efetividade de adoção das novas normas contábeis por parte dos futuros contadores.

\section{REVISÃO DA LITERATURA}

Este capítulo trata do processo de convergência das normas internacionais de contabilidade e do ensino de Teoria da Contabilidade no Brasil, bem como estudos anteriores sobre a disciplina de Teoria da Contabilidade.

\subsection{O Processo de Convergência das Normas Internacionais de Contabilidade no Brasil}

O propósito principal dos relatórios contábeis é de dar suporte à tomada de decisão de todos aqueles que têm interesse na empresa, ou seja, as demonstrações são voltadas para todos os usuários (HENDRIKSEN; VAN BREDA, 1999). Segundo O Pronunciamento Conceitual Básico do Comitê de Pronunciamentos Contábeis (CPC, 2013), o objetivo dos relatórios contábeis é o de fornecer informações sobre a posição financeira e patrimonial da entidade, que sejam úteis a grande número de usuários para a tomada de decisão.

Considerando que as demonstrações contábeis são divulgadas para atender os diversos usuários, surgiu a necessidade de um padrão de relatórios que sejam elaborados seguindo normas. A normatização contábil tem por objetivo garantir que esses relatórios divulgados sejam compreensíveis, comparáveis, confiáveis e relevantes. Em razão da existência dessas normas ocorre então a atuação dos órgãos reguladores e fiscalizadores (ANTUNES; GRECCO; FORMIGONI, 2012).

Fernandes et al. (2010) afirmam que a criação do Comitê de Pronunciamentos Contábeis (CPC) veio preencher o vazio que existia no Brasil quanto à centralização da emissão das normas contábeis brasileiras em relação 
às normas internacionais de contabilidade emitidas pelo International Accounting Standards Board (IASB).

O Conselho Federal de Contabilidade (CFC), por meio da Resolução no. 1.055/05, criou o Comitê de Pronunciamentos Contábeis (CPC), que é formado por membros de vários órgãos reguladores da contabilidade Brasileira: Associação Brasileira de Companhias Abertas (ABRASCA), Associação dos Analistas e Profissionais de Investimento do Mercado de Capitais (APIMEC Nacionais), Bolsa de Valores (BM\&FBOVESPA), Conselho Federal de Contabilidade (CFC), Fundação Instituto de Pesquisas Contábeis (FIPECAFI) e Instituto dos Auditores Independentes do Brasil (IBRACON). O CPC tem como objetivo de promover o estudo, o preparo e a emissão de pronunciamentos técnicos sobre a contabilidade e a divulgação de informações, levando-se em conta a convergência da contabilidade brasileira para os padrões internacionais (CPC, 2013).

São convidados para participar das reuniões do CPC representantes da Comissão de Valores Mobiliários (CVM), Secretaria da Receita Federal (SRF), Banco Central (BACEN) e Superintendência de Seguros Privados (SUSEP), devendo os pronunciamentos emitidos pelo CPC serem homologados por esses órgãos reguladores para serem aplicados no âmbito de cada um desses órgãos (BARBOSA; DIAS; PINHEIRO, 2009).

Com base nas normas contábeis internacionais, denominadas de International Accounting Standards (IAS) ou International Financial Reporting Standards (IFRS), emitidas pelo International Accounting Standards Board (IASB), - Comitê de Pronunciamentos Contábeis produziu 49 pronunciamentos técnicos, denominados CPCs, entre os anos de 2007 a 2011 (CPC, 2018).

Outro passo importante para a convergência aos padrões internacionais de contabilidade foi a promulgação da Lei $n^{\circ} 11.638 / 07$, que alterou e revogou dispositivos da Lei $n^{\circ}$ 6.404/76 sobre a elaboração e divulgação das demonstrações financeiras no país. Ainda em 2007, foi emitida a Instrução $n^{\circ}$ 457/2007 da CVM, que determinou que as IFRS fossem obrigatórias para as demonstrações financeiras consolidadas das sociedades anônimas abertas e as sociedades de grande porte, relativas ao exercício de 2010 em diante (DANTAS et al., 2010).

Esperanto et al. (2007) mencionam que a adaptação do Brasil à convergência passou por diversos obstáculos, dentre eles a falta de profissionais capacitados em IFRS, dentro e fora da área contábil. Existe uma crescente demanda por profissionais cada vez mais capacitados, e isto é consequência natural da competitividade vivenciada (HERNANDES; PELEIAS.; BARBALHO, 2006). E uma boa instrução aos profissionais de contabilidade é necessária.

\subsection{O Ensino de Teoria da Contabilidade no Brasil}

Segundo ludícibus, Martins e Carvalho (2005), antes da contabilidade ser ciência, o sistema de escrituração e o método das partidas dobradas eram sinônimos de contabilidade. Mas essa visão foi reformulada ao longo da história, em que a contabilidade recebeu diversos outros sentidos e significados. 
Com a evolução da contabilidade, a preocupação com os eventos econômicos relativos às entidades aumentou, sendo mais utilizada para transmitir aos seus usuários as condições econômicas e financeiras dos seus negócios (BORBA; POETA; VICENTE, 2011).

Como disciplina em cursos superiores, ela possui um histórico bastante recente, quando comparada, por exemplo, à economia. Os primeiros livros de teoria contábil propriamente ditos datam do final do século XIX, enquanto os de economia já eram conhecidos há mais tempo. A contabilidade demorou a pensar-se como teoria, em pesquisas e metodologias científicas (IUDICIBUS, 2012).

No Brasil, a primeira escola especializada no ensino da Contabilidade foi a Escola de Comércio Armando Álvares Penteado, criada em 1902, com os ensinamentos voltados à escola italiana. No entanto, os primeiros artigos científicos surgiram no Departamento de Ciências Contábeis e Atuariais da Faculdade de Economia, Administração e Contabilidade da Universidade de São Paulo - FEA/USP, a partir do pensamento contábil norte-americano (SACRAMENTO, 1998).

Theóphilo et al. (2000) afirmam que foi estabelecida com a Resolução no 003, de 05/10/1992, do Conselho Federal de Educação, a obrigatoriedade da disciplina de "Teoria da Contabilidade" na grade curricular dos cursos de Graduação em Ciências Contábeis no Brasil.

Ela se tornou necessária para que os acadêmicos tenham uma base conceitual de qualidade, atendendo às necessidades do mercado, pois é por meio de metodologias científicas que é possível explicar a realidade (MADEIRA; MENDONÇA; ABREU, 2003).

Sacramento (1998) menciona que para ter contadores com fundamentos científicos de contabilidade, com senso de respostas satisfatórias nos desafios profissionais, os responsáveis pela adequação curricular, ou até mesmo os docentes que lecionam a disciplina de Teoria da Contabilidade, devem fazer um estudo para conhecer o que é essa teoria e qual a sua importância na graduação.

O ensino da Teoria da Contabilidade deve aproximar a teoria e a prática, acontecendo de forma mais viva. Possuir o domínio da teoria ajuda a explicar e interpretar a prática de assuntos complexos, desenvolvendo habilidades necessárias para a profissão (MADEIRA; MENDONÇA; ABREU, 2003).

A disciplina Teoria da Contabilidade contribui para a formação do profissional contábil, pois ela proporciona o entendimento das normas e princípios fundamentais da contabilidade, dos seus conceitos e objetivos, abordando o pensamento contábil e promovendo a compreensão das teorias que fundamentam a contabilidade (MADEIRA; MENDONÇA; ABREU, 2003).

Dentre essas normativas da profissão contábil, se encontram as normas internacionais de contabilidade. Com a adesão brasileira a essa normatização contábil internacional, tornou-se necessário que os profissionais tenham uma boa base teórica, para que possam resolver problemas que não estejam 
previstos nesses dispositivos (BORBA; POETA; VICENTE, 2011), o que reforça a importância da disciplina de Teoria da Contabilidade.

A convergência às normas contábeis internacionais, principalmente por meio da Lei no. 11.638/07, trouxe profundas modificações na forma de fazer e visualizar a Contabilidade quanto à estrutura, abrangência, reconhecimentos e divulgação das informações contábeis (ESPEJO et al., 2010). Tal fato provocou mudanças em várias disciplinas dos cursos de Ciências Contábeis, dentre elas a de Teoria da Contabilidade.

Foram realizadas alterações no Balanço Patrimonial das empresas, com a subdivisão do ativo e do passivo em circulante e não circulante, a criação do subgrupo intangível, alterações nas normas de classificação das contas do imobilizado, uma nova subdivisão do patrimônio líquido, entre outras modificações (ESPEJO et al., 2010). Os CPCs emitidos servem como base para fazer essas alterações e é por meio deles, que os docentes transmitem os ensinamentos aos acadêmicos, relacionados às alterações advindas do processo de convergência das normas internacionais de contabilidade.

A importância da disciplina Teoria da Contabilidade nos cursos de graduação em Ciências Contábeis é justificada, pois ela proporciona maior respaldo e uma compreensão adequada na utilização da contabilidade e suas práticas (LIMA FILHO; BRUNI, 2012).

\subsection{Estudos Relacionados}

Várias são as pesquisas encontradas sobre o ensino da contabilidade no Brasil, além das que dizem respeito às alterações ocorridas com a Lei no. 11.638/07. Os estudos se tornam relevantes pelas crescentes mudanças no cenário contábil com o processo de convergência das normas internacionais de contabilidade.

Dentre as diversas pesquisas, pode-se citar a de Marion (1997), que abordou algumas considerações da disciplina de Teoria da Contabilidade nos cursos de graduação. De acordo com o autor, utilizava-se como recurso didático, mostrar que a Teoria está constantemente contribuindo com a arte de bem informar o usuário e explicando como isto processa. No período deste estudo, o conteúdo programático da disciplina Teoria da Contabilidade tinha como foco o escorço histórico, os objetivos da contabilidade e das demonstrações contábeis, a contabilidade como ciência social, a qualidades da informação contábil, os princípios fundamentais da contabilidade, ativo (conceito e mensuração), passivo, patrimônio líquido, receitas, despesas, perdas e ganhos, demonstrações contábeis, normas contábeis brasileiras.

A pesquisa de Sacramento (1998) teve como objetivo analisar a necessidade de conhecimentos científicos por parte dos professores da disciplina de Teoria da Contabilidade. A autora utilizou um questionário direcionado aos professores desta disciplina. Concluiu que aqueles que não a cursaram na graduação, nem em cursos de pós-graduação, deveriam munir-se de conhecimentos científicos, apresentando os conceitos, metodologias e os princípios de contabilidade que são utilizados na teoria. 
Theóphilo et al. (2000) verificaram como vem sendo ministrada a disciplina Teoria da Contabilidade nos cursos de graduação em Ciências Contábeis no Brasil. Como achados deste estudo, pode-se mencionar que a disciplina Teoria da Contabilidade, quanto a carga horária possuía em média 60 horas ou mais, havia como pré-requisito ter cursado a disciplina de Contabilidade Geral, os principais conteúdos trabalhados eram postulados, Princípios e Convenções Contábeis, seguido de origem e evolução da contabilidade, após ainda objetivos, bases conceituais e metodológicas. Concluíram que ela passou a ser oferecida pelas diversas instituições de ensino em períodos totalmente distintos, variando do primeiro ao último período do curso. Isso faz com que o enfoque dado à disciplina seja bastante diferenciado, desprezando-se o verdadeiro valor da Teoria da Contabilidade.

A pesquisa de Madeira, Mendonça e Abreu (2003) teve como objetivo analisar os resultados das avaliações do Exame de Suficiência e do Exame Nacional de Cursos (Provão), de 24 faculdades do Estado de Minas Gerais, verificando o desempenho das faculdades em análise e apontando deficiências relacionadas ao ensino de Teoria da Contabilidade. Como resultados do estudo, pode-se destacar que quanto à carga horária faltava uniformidade na amostra, a maioria das faculdades adotava 72 horas, mas existia oscilação entre 60 horas e 138 horas. Também ocorria oscilação em relação ao ano do curso de oferta disciplina, houve oferta do primeiro ao quarto ano, no entanto o mais ofertado foi o terceiro ano, representando $32 \%$ da amostra. A bibliografia mais utilizada foi a obra Teoria da Contabilidade de Sérgio Iudícibus. Quanto aos conteúdos trabalhos na disciplina, foram encontrados 53 conteúdos diferentes entre as faculdades pesquisadas, no entanto, alguns conteúdos comuns foram: ativo e sua avaliação; convenções contábeis; evidenciação; normas brasileiras de contabilidade; objetivos da contabilidade; origem e evolução histórica da contabilidade; passivo e sua mensuração; patrimônio líquido; postulados contábeis; princípios fundamentais de contabilidade; e receitas, despesas, perdas e ganhos.

Espejo et al. (2010) analisaram como a Universidade Federal do Paraná está adaptando o ensino no curso de ciências contábeis aos preceitos da Lei no. 11.638/07. Para tal, desenvolveram uma investigação de caráter formal, ex post facto, descritiva, aplicada por meio de um questionário aos alunos do $1^{\circ}$ e $4^{\circ}$ ano. Os resultados apontaram que a instituição está promovendo adaptações no ensino em resposta às alterações constantes da Lei no. 11.638/07.

Borba, Poeta e Vicente (2011) pesquisaram a disciplina de Teoria da Contabilidade nos programas de mestrado no Brasil. Verificaram as ementas e bibliografias desta disciplina, comparando os programas brasileiros com alguns mestrados dos Estados Unidos da América (EUA). Concluíram que existe uma lógica no ensino da Teoria da Contabilidade pelos programas de mestrado, mas nos programas norte-americanos, verificou-se escassa oferta específica dessa disciplina.

A pesquisa de Soares, Silva e Pfitscher (2011) teve como objetivo analisar quais os conteúdos são tratados nas disciplinas de Teoria da Contabilidade dos Cursos de Ciências Contábeis das Universidades Federais Brasileiras. Referente aos temas abordados no decorrer da disciplina, os autores destacaram como 
resultados que o conteúdo mais recorrente se refere aos Princípios e Convenções Contábeis adotados na contabilidade. Além, desse conteúdo vale ressaltar a existência de outros também relevantes, como: origem e evolução da contabilidade; ativo, passivo, patrimônio líquido e suas avaliações; receitas, despesas, perdas e ganhos; o campo de atuação da contabilidade; e estruturação do patrimônio, Quanto ao período de oferta disciplina no curso, a maioria das instituições pesquisadas ofertam a disciplina geralmente nos semestres cinco e seis. No que tange à carga horária, verificou-se que a maior parte das instituições disponibiliza para a disciplina 60 horas-relógio ou 72 horasaula. Quanto às bibliografias utilizadas, mesmo que a lista de sugestão de bibliografias pelas universidades federais é bastante abrangente e diversificada, destacou-se que o livro Teoria da Contabilidade do autor Sérgio de Iudícibus está elencado dentre as sugestões da maioria das instituições,

Lima Filho e Bruni (2012) buscaram entender como o ensino da disciplina de Teoria da Contabilidade em cursos de graduação de Salvador, Bahia, contribuiu para o domínio de conceitos relevantes da Contabilidade, como por exemplo, conceitos de ativo, passivo, receitas, despesas, ganhos, perdas e goodwill. A amostra foi composta por 591 acadêmicos matriculados no curso de Ciências Contábeis que já haviam frequentado a disciplina. Os resultados evidenciaram falhas na compreensão destes conceitos, indicaram também que alunos de instituições públicas possuem melhor domínio, a compreensão melhora quando a titulação do docente evolui de especialista para mestre e deste para doutor.

Ferreira et al. (2013) identificaram como a Teoria da Contabilidade é abordada nos cursos de graduação e pós-graduação em contabilidade nas melhores universidades estrangeiras. Por meio de questionário, foram levantados dados de 25 docentes de 20 universidades diferentes. Os resultados apontam que apenas cinco das 20 universidades possuem especificamente a disciplina de Teoria da Contabilidade. As demais adéquam seu conteúdo a outras disciplinas, como em Contabilidade Introdutória, Intermediária e Avançada. Diferentemente do Brasil, em que é obrigatória a disciplina de Teoria da Contabilidade, as universidades estrangeiras optam por abordar o seu conteúdo de forma integrada. O principal objetivo de ensinar Teoria da Contabilidade, mencionado pelos docentes pesquisados, é para que os alunos aprendam os princípios, as normas contábeis e suas mudanças. Eles afirmaram também que os alunos conseguem relacionar os conteúdos de Teoria da Contabilidade abordados em sala com a prática da profissão, porém não mencionam de que forma é feita essa relação.

O trabalho de Rosa et al. (2012) teve como objetivo identificar e analisar a legitimidade sociopolítica e cognitiva, visando à busca de identidade da disciplina Teoria da Contabilidade. Os autores encontraram como resultados, que o conteúdo mais recorrente nas ementas das instituições analisadas foi Princípios e Convenções Contábeis adotados na contabilidade. Além desse conteúdo vale ressaltar a existência de outros também relevantes, como: origem e evolução da contabilidade; ativo, passivo, patrimônio líquido; receitas, despesas, perdas e ganhos; o campo de atuação; estruturação do patrimônio. Assim como, quanto as bibliográficas utilizadas na disciplina Teoria da 
Contabilidade, os livros de ludícibus e Marion (2009) e de Niyama e Silva (2009) são indicados para uso em cursos de graduação em Ciências Contábeis.

Soares e Vicente (2014) analisaram os conteúdos encontrados nos modernos livros de Teoria da Contabilidade brasileiros utilizados nas salas de aula de todo o país, tendo como amostra sete livros publicados, entre 1979 e 2009, pela Editora Atlas. Pode-se identificar que nenhum tópico levantado foi recorrente em todas as obras, embora alguns tópicos tenham sido mais frequentes que os restantes, como: metodologia, objeto e objetivos, princípios, postulados e convenções, mensuração de ativos e passivos, patrimônio líquido e pesquisa em contabilidade são mais recorrentes nos livros de Teoria da Contabilidade.

O estudo de Piccoli, Chiarello e Klann (2015) teve por objetivo identificar a percepção dos acadêmicos do Curso de Ciências Contábeis em relação a conceitos estudados na disciplina de Teoria da Contabilidade e sua relação com as demais disciplinas do curso. Para tal, foi enviado um questionário estruturado aos alunos regularmente matriculados em três Universidades do Oeste e Extremo Oeste do Estado de Santa Catarina. Como resultados destacase, que para os acadêmicos pesquisados os conceitos mais simples de ativos e passivos são os mais percebidos. O mesmo foi observado para os conceitos de receita e despesa. No entanto, tal achado difere-se aos conceitos de perda e ganho para os pesquisados, que quando questionados, apontaram conceitos mais completos, extraídos do CPC 00.

ludícibus, Beuren e Santos (2016) analisaram como o ensino da Teoria da Contabilidade ocorre nos 27 Programas de Pós-Graduação de Ciências Contábeis do Brasil. Referente os resultados, todos os 27 programas oferecem a disciplina de Teoria da Contabilidade no curso de mestrado, mesmo que em alguns casos com designação diferente, mas com o mesmo conteúdo. Já nos cursos de doutorado denota-se que a obrigatoriedade da disciplina não acontece de forma unânime como nos cursos de mestrado. Dentre os conteúdos abordados, verificaram-se similaridades nos programas pesquisados, com temas relacionados à critérios de reconhecimento e mensuração de ativos, passivos, patrimônio líquido, receitas e despesas. Aspectos relacionados à evolução histórica e desenvolvimento da contabilidade, estrutura conceitual, evidenciação contábil também se destacaram. No que tange as formas de avaliação adotadas pelos docentes, destacaram-se seminários, provas, artigos e a participação atividades realizadas no decorrer do trimestre ou semestre, como resenhas, análises, exercícios, debates em aula, estudos de casos.

O estudo de Souza e Vicente (2017) teve como objetivo identificar a compreensão dos graduandos do curso de Ciências Contábeis quanto aos conceitos relevantes ensinados na disciplina de Teoria da Contabilidade, tendo como amostra, as instituições de ensino dos municípios de Florianópolis, São José, Biguaçu e Palhoça, do estado de Santa Catarina. Dentre os resultados, observou-se que os alunos percebem os conceitos de Teoria da Contabilidade mais ligados à normatização, dado que a maior parte dos alunos considerou o conceito publicado pelos CPCs, como sendo aquele que mais representa o seu entendimento acerta dos conceitos pesquisados. Tal resultado indica uma 
implicação com o atual momento de convergência para as normas internacionais de contabilidade.

Cunha, Guidini e Klann (2017) identificaram a percepção dos professores dos Programas de Pós-Graduação Stricto Sensu em Ciências Contábeis (PPGCCS) do Brasil sobre a abordagem da disciplina Teoria da Contabilidade no cenário da convergência às Normas Internacionais de Contabilidade. Os resultados identificaram que quanto aos conteúdos mais enfatizados pelos professores foram o ativo e sua mensuração, o passivo e sua mensuração, receitas, despesas, ganhos e perdas e patrimônio líquido. Os temas de reconhecimento, mensuração e evidenciação são conteúdos que estão sendo discutidos no processo de convergência das normas internacionais de contabilidade. Sobre a importância disciplina para o mestrado, os resultados apontaram que os professores ressaltam que os alunos necessitam estudar as teorias para fundamentar as definições e conceitos da contabilidade, e precisam aprofundar conhecimentos sobre pressupostos econômicos que influenciam a prática e o modelo decisório. As respostas relativas ao doutorado indicam a necessidade de integração da Teoria da Contabilidade com outras áreas do conhecimento, e que a disciplina contribui para a evolução da pesquisa contábil.

\section{PROCEDIMENTOS METODOLÓGICOS}

A presente pesquisa se classifica como descritiva, que segundo Alves, Behr e Raimundini (2012), possui como objetivo a análise e a observação dos fatos, partindo de uma perspectiva de registro, análise e, por fim, sendo possível relatar os fenômenos e compará-los. Em relação ao tipo de pesquisa, esta possui caráter quantitativo, que geralmente é aplicado em pesquisas com abordagem descritiva. Segundo Martins e Theóphilo (2007, p. 135), "a pesquisa quantitativa é aquela em que os dados e as evidências coletados podem ser quantificados, mensurados".

\subsection{População e amostra}

Caracterizam-se como população deste estudo os docentes da disciplina de Teoria da Contabilidade das instituições de ensino superior do Estado do Paraná, representando um total de 84 instituições. Quanto à amostra, esta é definida pelo número de questionários respondidos, dos que foram enviados aos docentes da disciplina Teoria da Contabilidade de cursos de graduação em Ciências Contábeis presentes nas instituições de ensino do Estado do Paraná. De 84 instituições, que caracterizaram o total da população, a amostra obtida foi de 30 docentes que devolveram o questionário respondido.

Foi destacado como critério de pré-requisito para o professor responder o questionário, que o mesmo ministrasse a disciplina Teoria da Contabilidade desde o período anterior ao processo convergência das normas internacionais de contabilidade no Brasil, ou seja, antes de 2007, até o período posterior a tais mudanças. Caso contrário, o respondente não traria dados que contribuiriam com o alcance do objetivo do presente estudo. 
A escolha do Estado do Paraná como local da pesquisa se deve por ser um Estado com grande número de instituições de ensino que oferecem o curso de Ciências Contábeis, ficando na terceira colocação no Brasil, perdendo apenas para São Paulo e Minas Gerais (MEC, 2013). Outro motivo pela preferência da pesquisa ter sido neste Estado se deve pela maior acessibilidade dos pesquisadores às instituições de ensino deste do Paraná.

\subsection{Coleta e análise dos dados}

O procedimento de coleta dos dados foi realizado por meio de levantamento, realizado com o envio de um questionário, que foi desenvolvido em modelo de Escala Likert de cinco pontos, possuindo como tema as modificações no ensino da disciplina Teoria da Contabilidade após o processo de convergência às normas contábeis internacionais.

O questionário foi elaborado pelos autores do presente estudo, com base nas alterações advindas da Lei 11.638/07 com enfoque em conteúdos trabalhados na disciplina Teoria da Contabilidade. Para verificar a confiabilidade do instrumento de coleta de dados, foi realizado o pré-teste com dois professores atuantes na disciplina Teoria da Contabilidade, que indicaram contribuições para reforçar o conteúdo e estrutura do questionário com o objetivo do presente estudo.

O Quadro 1 apresenta o questionário enviado para os docentes da disciplina de Teoria da Contabilidade das instituições paranaenses pesquisadas.

\section{Quadro 1 - Questionário sobre alteraçōes na disciplina Teoria da Contabilidade}

O processo de convergência das normas contábeis brasileiras às normas contábeis internacionais alterou diversos conceitos que são trabalhados na disciplina de Teoria da Contabilidade nos cursos de graduação. Assinale em uma escala de 1 (discordo plenamente) a 5 (concordo plenamente) as principais modificações no conteúdo e na didática desta disciplina em relação as seguintes modificações:

\begin{tabular}{|l|l|}
\hline \multicolumn{1}{|c|}{ Questão } & Pontuação \\
\hline $\begin{array}{l}\text { 1-Quanto ao conceito de ativo, houve modificação no conteúdo transmitido } \\
\text { aos alunos. }\end{array}$ & \\
\hline $\begin{array}{l}\text { 2- Quanto à criação do grupo de contas Ativos Intangíveis, essa modificação } \\
\text { alterou de modo significativo a abordagem deste tema na disciplina. }\end{array}$ & \\
\hline $\begin{array}{l}\text { 3 - Quanto à criação do grupo de Ativo Intangível, o termo Goodwill, que } \\
\text { caracteriza um ágio pago na expectativa de rentabilidade futura, resultou em } \\
\text { dificuldades na prática docente para trabalhar com esse ativo não identificável, } \\
\text { que tem origem de difícil definição. }\end{array}$ & \\
\hline $\begin{array}{l}4 \text { - Quanto ao conceito de Passivo, foi necessário modificar o conteúdo } \\
\text { transmitido aos alunos. }\end{array}$ & \\
\hline $\begin{array}{l}5 \text { - Quanto às modificações na composição do Patrimônio Líquido levaram a } \\
\text { modificações no conteúdo da disciplina. }\end{array}$ & \\
\hline 6 - Quanto às modificações nas Receitas, houve alteração no conteúdo & \\
\hline \hline
\end{tabular}




\begin{tabular}{|c|}
\hline $\begin{array}{l}\text { 7 - Quanto às modificações nas Despesas, foram necessárias alterações no } \\
\text { conteúdo transmitido aos acadêmicos. }\end{array}$ \\
\hline $\begin{array}{l}8 \text { - Quanto às modificações na estrutura das demonstrações contábeis, houve } \\
\text { necessidade de adequação do conteúdo da disciplina. }\end{array}$ \\
\hline $\begin{array}{l}\text { 9- Quando ao Comitê de Pronunciamentos Contábeis (CPC), que foi estruturado } \\
\text { para acompanhar o processo de convergência contábil no Brasil. O docente da } \\
\text { disciplina de Teoria da Contabilidade está fazendo uso de seus pronunciamentos } \\
\text { para auxiliar suas aulas. }\end{array}$ \\
\hline $\begin{array}{l}10 \text { - Quanto à eficácia dos pronunciamentos do CPC estão ao transmitir para o } \\
\text { aluno novos conceitos relacionados ao processo de convergência. }\end{array}$ \\
\hline $\begin{array}{l}11 \text { - Quanto às Perdas: a exigência de se reconhecer perdas por } \\
\text { irrecuperabilidade do valor contábil do ativo (impairment) levou a modificações } \\
\text { relevantes no conteúdo da disciplina. }\end{array}$ \\
\hline $\begin{array}{l}12 \text { - Quanto à criação da conta de Ajuste de Avaliação Patrimonial, resultou em } \\
\text { modificação no conteúdo da disciplina. }\end{array}$ \\
\hline $\begin{array}{l}13 \text { - Quando às novas formas de contabilização do leasing, levaram a } \\
\text { modificações no conteúdo da disciplina, principalmente quanto ao } \\
\text { reconhecimento de ativos. }\end{array}$ \\
\hline $\begin{array}{l}14 \text { - Quanto às novas normas relativas às depreciações, incluindo conceitos } \\
\text { como valor residual, taxas efetivas ao invés de fiscais, ocasionaram modificações } \\
\text { importantes na disciplina de Teoria da Contabilidade. }\end{array}$ \\
\hline $\begin{array}{l}15 \text { - Quanto à modificação do Art. } 177 \text { da Lei 6.404/76, os registros contábeis em } \\
\text { desacordo com a Lei } 11.638 / 07 \text {, para atender à legislação tributária ou para } \\
\text { atender outra legislação em função do objeto da Companhia, devem ser feitos } \\
\text { em registros auxiliares. Tal alteração levou a modificação no conteúdo da } \\
\text { disciplina. }\end{array}$ \\
\hline $\begin{array}{l}16 \text { - Quanto às características qualitativas da informação contábil, } \\
\text { contempladas no CPC 00, resultaram em modificações significativas na disciplina } \\
\text { Teoria da Contabilidade, principalmente quanto ao ensino dos postulados, } \\
\text { princípios e convenções contábeis. }\end{array}$ \\
\hline
\end{tabular}

Fonte: Elaborado pelos autores.

Ainda no procedimento para coleta de dados, o segundo bloco do mesmo questionário, também em Escala Likert de cinco pontos, tratou exclusivamente sobre o uso do CPC nas práticas docentes, conforme apresentado no Quadro 2. 


\section{Quadro 2 - Modificações trazidas pelos CPCS na disciplina Teoria da Contabilidade}

\begin{tabular}{|c|c|}
\hline CPC & Nota \\
\hline \multicolumn{2}{|l|}{ CPC 00 - Pronunciamento Conceitual Básico } \\
\hline \multicolumn{2}{|l|}{ CPC 01 - Redução ao Valor Recuperável de Ativos } \\
\hline \multicolumn{2}{|c|}{$\begin{array}{l}\text { CPC } 02 \text { - Efeitos das Mudanças nas Taxas de Câmbio e Conversão de } \\
\text { Demonstrações Contábeis }\end{array}$} \\
\hline \multicolumn{2}{|l|}{ CPC 04 - Ativo Intangível } \\
\hline \multicolumn{2}{|l|}{ CPC 12 - Ajuste a Valor Presente } \\
\hline \multicolumn{2}{|l|}{ CPC 18 - Investimento em Coligada e em Controlada } \\
\hline \multicolumn{2}{|l|}{ CPC 27 - Ativo Imobilizado } \\
\hline \multicolumn{2}{|l|}{ CPC 29 - Ativo Biológico e Produto Agrícola } \\
\hline \multicolumn{2}{|l|}{ CPC 33 - Benefícios a Empregados } \\
\hline CPC 38 - Instrumentos Financeiros: Reconhecimento e Mensuração & \\
\hline Sugestão do pesquisado: & \\
\hline
\end{tabular}

Fonte: Elaborado pelos autores.

Foram selecionados os CPCs, mencionados no Quadro 2, pois de acordo com a percepção dos autores do estudo, reforçados pelo pré-teste do instrumento de coleta de dados, foram os pronunciamentos com maior relação à disciplina Teoria da Contabilidade. Mesmo com tal indicação, para não limitar os respondentes e até mesmo identificar achados que indiquem o uso de outros pronunciamentos como ensino na disciplina em análise, foi inserido no instrumento o item "sugestão do pesquisado", assim o respondente teve a opção de mencionar o uso de outro CPC como resposta.

Após o procedimento de coleta de dados, a análise foi realizada por meio de estatística descritiva, em que foram apurados dados como, mínimo, máximo e moda para obter os resultados, alcançando o objetivo proposto por esta pesquisa.

Além da estatística descritiva, foi aplicado o grau de entropia da informação nos resultados, para verificar quais questões, por meio de seu peso informacional, tem maior variabilidade nos dados em relação ao objetivo. Rocha (2010) afirma que a entropia objetiva caracterizar o grau de variação das respostas e, em consequência disso, sua maior concordância. Rodrigues, Zonatto e Lavarda (2012) apontam que quanto mais próximo o valor do peso 
informacional de cada questão estiver de um, menor a variabilidade e maior o consenso com o objetivo.

Tanto para o cálculo da estatística descritiva, quanto para o grau de entropia da informação, foi utilizado o software Excel como auxílio à quantificação e análise dos dados.

\section{DESCRIÇÃO E ANÁLISE DOS DADOS}

O primeiro bloco do questionário foi dividido em duas partes. A primeira parte abrange as questões de 1 a 8 e 11, 12 e 14, que tratam da composição das contas patrimoniais e de resultado. A segunda parte abrange as questões 9 , 10,13, 15 e 16, que tratam das modificações na normatização. O questionário, com Escala Likert de cinco pontos, foi respondido por 30 docentes, em que a variação ocorria de 1 (discordo totalmente) até 5 (concordo totalmente). A Tabela 1 apresenta as respostas da primeira parte do primeiro bloco.

Tabela 1 - Modificação na composição das contas Patrimoniais e de Resultado

\begin{tabular}{|c|c|c|c|c|c|c|c|c|c|c|c|c|}
\hline & & Q1 & Q2 & Q3 & Q4 & Q5 & Q6 & Q7 & Q8 & Q11 & Q12 & Q14 \\
\hline \multirow{2}{*}{$N$} & Válido & 30 & 30 & 30 & 30 & 30 & 30 & 30 & 30 & 30 & 30 & 30 \\
\hline & Ausente & 0 & 0 & 0 & 0 & 0 & 0 & 0 & 0 & 0 & 0 & 0 \\
\hline \multicolumn{2}{|c|}{ Moda } & 4 & 4 & 4 & 2 & 4 & 4 & 4 & 5 & 4 & 4 & 5 \\
\hline \multicolumn{2}{|c|}{ Mínimo } & 1 & 2 & 1 & 1 & 1 & 2 & 2 & 1 & 2 & 3 & 3 \\
\hline \multicolumn{2}{|c|}{ Máximo } & 5 & 5 & 5 & 5 & 5 & 5 & 5 & 5 & 5 & 5 & 5 \\
\hline \multicolumn{2}{|c|}{$\begin{array}{l}\text { Peso } \\
\text { Informacional }\end{array}$} & 0,142 & 0,090 & 0,199 & 0,147 & 0,074 & 0,048 & 0,086 & 0,099 & 0,049 & 0,035 & 0,033 \\
\hline
\end{tabular}

Fonte: Elaborada pelos autores.

Analisando o indicador Moda na Tabela 1, percebe-se que na maioria das questões os respondentes concordam com a modificação que foi afirmada. Quando se perguntou sobre as modificações na estrutura das demonstrações contábeis (Q.8), se houve necessidade de adequação do conteúdo da disciplina e se as novas normas relativas às depreciações, incluindo conceitos como valor residual, taxas efetivas ao invés de fiscais (Q.14), ocasionaram modificações importantes na disciplina de Teoria da Contabilidade, a maior parte dos respondentes concordou plenamente com essa afirmação. Apenas na questão que indagou o conceito de Passivo (Q.4), se foi necessário modificar o conteúdo transmitido aos alunos, a discordância foi a resposta que prevaleceu.

As pesquisas de Marion (1997), Theóphilo et al. (2000), Madeira, Mendonça e Abreu (2003), Soares, Silva e Pfitscher (2001), Rosa et al. (2012) e Soares e Vicente (2014) apresentam como achado que o conceito de Passivo está entre os conteúdos de maior abrangência, em instituições de ensino 
diferentes, na disciplina Teoria da Contabilidade. Sendo assim, comparando tal achado com os resultados da Questão 4 do presente estudo, entende-se que o processo de convergência às normas internacionais de contabilidade não alterou o conteúdo transmitido aos alunos, no que tange ao Passivo. Dessa forma no Brasil, vem se mantendo o padrão quanto ao ensino deste conceito patrimonial.

Pelo cálculo da entropia, apurou-se que a média do peso informacional das questões apresentadas na Tabela 1 foi de 0,09. Portanto, quando se perguntou se a criação do grupo de contas Ativos Intangíveis alterou de modo significativo a abordagem deste tema na disciplina (Q.2), nota-se que a concordância dos respondentes em relação a esta indagação se iguala à média do peso informacional desse grupo de questões.

Ao se analisar as seguintes indagações: se a exigência de se reconhecer perdas por irrecuperabilidade do valor contábil do ativo (impairment) levou a modificações relevantes no conteúdo da disciplina (Q.11); se a criação da conta de Ajuste de Avaliação Patrimonial resultou em modificação no conteúdo da disciplina (Q.12); e se as novas normas relativas às depreciações ocasionaram modificações importantes na disciplina de Teoria da Contabilidade (Q.14); a entropia da informação permite afirmar que tais questões apresentam um consenso forte entre os respondentes, pois apresentaram seu peso informacional abaixo de 0,09 e ao mesmo tempo uma média alta em relação à concordância, o que permite notar que para este grupo de questões, essas indagações apresentam uma concordância consistente dos respondentes em relação ao objetivo deste estudo.

Algumas questões como: quanto ao conceito de ativo, se houve modificação no conteúdo transmitido aos alunos (Q.1); se com a criação do grupo de Ativo Intangível, o termo Goodwill resultou em dificuldades na prática docente para trabalhar com esse ativo não identificável, que tem origem de difícil definição (Q.3); e quanto ao conceito de Passivo, se foi necessário modificar o conteúdo transmitido aos alunos (Q.4); apresentaram peso informacional com valor acima da média da entropia $(0,09)$. Tais resultados permitem inferir que para essas questões houve grande variabilidade na opinião dos respondentes.

Na Tabela 2 é apresentada a segunda parte do primeiro bloco de questões, sobre os resultados relativos às modificações na normatização apontadas pelos docentes.

Tabela 2 - Modificações na normatização

\begin{tabular}{l|l|c|c|c|c|c}
\hline \multicolumn{2}{l|}{} & Q9 & Q10 & Q13 & Q15 & Q16 \\
\hline \multirow{2}{*}{$N$} & Válido & 30 & 30 & 30 & 30 & 30 \\
\cline { 2 - 7 } & Ausente & 0 & 0 & 0 & 0 & 0 \\
\hline Moda & 5 & 4 & 4 & 4 & 5 \\
\hline Mínimo & 2 & 2 & 2 & 2 & 2 \\
\hline
\end{tabular}




\begin{tabular}{l|c|c|c|c|c}
\hline Máximo & 5 & 5 & 5 & 5 & 5 \\
\hline Peso Informacional & 0,149 & 0,235 & 0,178 & 0,206 & 0,233 \\
\hline
\end{tabular}

Fonte: Elaborada pelos autores.

De acordo com os dados da Tabela 2, o indicador moda apresenta que em $60 \%$ das questões dessa parte do questionário, a resposta que prevaleceu foi que os especialistas concordam que as modificações trazidas pelo processo de convergência às normas contábeis internacionais causaram alterações no ensino da disciplina Teoria da Contabilidade (Q.15). Este achado corrobora com o estudo de Espejo et al. (2010), que afirmou que a instituição de ensino em pesquisa está promovendo adaptações no ensino em resposta às alterações constantes da Lei no. 11.638/07.

Ainda houve $40 \%$ das questões em que a moda indica que os respondentes concordam plenamente que o Comitê de Pronunciamentos Contábeis (CPC) foi estruturado para acompanhar o processo de convergência contábil no Brasil (Q.9); o docente da disciplina de Teoria da Contabilidade está fazendo uso de seus pronunciamentos para auxiliar suas aulas; e que as características qualitativas da informação contábil, contempladas no CPC 00, resultaram em modificações significativas na disciplina Teoria da Contabilidade, principalmente quanto ao ensino dos postulados, princípios e convenções contábeis.

Dessa forma, os resultados do presente estudo sobre a concordância dos docentes, quanto ao uso do CPC como instrumento de auxílio para aulas corroboram a pesquisa de Souza e Vicente (2017), que dentre seus resultados, observou-se que os alunos da disciplina Teoria da Contabilidade consideram os conceitos publicados pelos CPCs, como sendo aquele que mais representa 0 seu entendimento acerta dos conceitos pesquisados.

Analisando o indicador mínimo da Tabela 2, percebe-se que não houve nenhuma das questões em que algum dos pesquisados discorda totalmente do assunto, o ponto mínimo de respostas que a escala obteve foi 2, representando apenas "discordo". O indicador máximo mostra que para todas as questões houve respondentes que concordaram plenamente com o assunto tratado. Tal fato demonstra que o grau de concordância sobre as modificações na normatização que alteraram o ensino da disciplina Teoria da Contabilidade é mais forte que a discordância.

A entropia de informações calculada no grupo de questões da Tabela 2 apresentou uma média de 0,20 . Diferente do resultado apresentado no primeiro grupo de questões, dessa vez não houve nenhum questionamento que teve seu peso informacional igual à média da entropia para o grupo de questões.

Os questionamentos sobre se o docente da disciplina de Teoria da Contabilidade está fazendo uso dos pronunciamentos do Comitê de Pronunciamentos Contábeis (CPC) para auxiliar suas aulas (Q.9); e se as novas formas de contabilização do leasing levaram a modificações no conteúdo da disciplina (Q.13); apresentaram peso informacional abaixo da média da entropia. Além disso, suas médias em relação à concordância da afirmação 
resultaram em um valor alto, comparado com as demais indagações desse grupo. Por meio desses resultados, nota-se que essas duas questões possuem um bom nível de concordância.

Devido ao peso informacional apresentar-se acima da média da entropia, quando indagado se os pronunciamentos do CPC estão sendo eficazes ao transmitir para o aluno novos conceitos relacionados ao processo de convergência (Q.10); e se as características qualitativas da informação contábil, contempladas no CPC 00, resultaram em modificações significativas na disciplina Teoria da Contabilidade (Q.16); entende-se para tais questionamentos houve grande variabilidade na opinião dos respondentes e não foi exibida alta concordância sobre o objetivo do estudo.

A Tabela 3 apresenta as estatísticas descritivas referentes ao segundo bloco de questões, que trata dos CPCs que trouxeram modificações relevantes para o conteúdo da disciplina de Teoria da Contabilidade.

Tabela 3 - CPCs que trouxeram modificações relevantes para o conteúdo da disciplina Teoria da Contabilidade

\begin{tabular}{|c|c|c|c|c|c|c|c|c|c|c|c|}
\hline & & $\begin{array}{l}\text { CPC } \\
00\end{array}$ & $\begin{array}{l}\text { CPC } \\
01\end{array}$ & $\begin{array}{l}\text { CPC } \\
02\end{array}$ & $\begin{array}{l}\text { CPC } \\
04\end{array}$ & $\begin{array}{l}\text { CPC } \\
12\end{array}$ & $\begin{array}{l}\text { CPC } \\
18\end{array}$ & $\begin{array}{l}\text { CPC } \\
27\end{array}$ & $\begin{array}{l}\text { CPC } \\
29\end{array}$ & $\begin{array}{c}\text { CPC } \\
33\end{array}$ & $\begin{array}{c}\text { CPC } \\
38\end{array}$ \\
\hline \multirow{2}{*}{ N } & Válido & 30 & 30 & 29 & 29 & 29 & 29 & 30 & 30 & 30 & 30 \\
\hline & Ausente & 0 & 0 & 1 & 1 & 1 & 1 & 0 & 0 & 0 & 0 \\
\hline \multicolumn{2}{|c|}{ Moda } & 4 & 4 & 2 & 5 & 5 & 4 & 4 & 3 & 3 & 4 \\
\hline \multicolumn{2}{|c|}{ Mínimo } & 1 & 3 & 2 & 2 & 3 & 1 & 2 & 2 & 1 & 2 \\
\hline \multicolumn{2}{|c|}{ Máximo } & 5 & 5 & 5 & 5 & 5 & 5 & 5 & 5 & 5 & 5 \\
\hline \multicolumn{2}{|c|}{$\begin{array}{l}\text { Peso } \\
\text { Informacional }\end{array}$} & 0,149 & 0,003 & 0,007 & 0,003 & 0,001 & 0,003 & 0,002 & 0,002 & 0,002 & 0,001 \\
\hline
\end{tabular}

Fonte: Elaborada pelos autores.

O indicador moda expresso na Tabela 3 mostra que quanto ao uso do CPC 00, CPC 01, CPC 18, CPC 27 e CPC 38, a maioria dos docentes concorda que estes pronunciamentos trouxeram modificações relevantes para $O$ conteúdo da disciplina Teoria da Contabilidade e concordam plenamente com a mesma afirmação referente ao uso do CPC 04 e do CPC 12. Quanto ao CPC 02 , os pesquisados discordam que este pronunciamento trouxe modificações relevantes para o conteúdo da disciplina Teoria da Contabilidade. Já quanto ao CPC 29 e CPC 33, o indicador moda mostrou indiferença por parte dos pesquisados.

Na Tabela 3, o ponto 2 da Escala Likert (discordo) foi o indicador mínimo que se manteve para o maior número de CPCs da pesquisa, representado pelos CPCs 02, 04, 27, 29 e 38. Enquanto que para o CPC 01 e CPC 12 não houve nenhum dos pesquisados que discordou dessa afirmação, o ponto menor que a escala desses CPCs obteve foi o 3, que representa indiferença ao assunto. 
Sendo assim, relacionando essa afirmação do indicador mínimo com os outros indicadores de avaliação apresentados na Tabela 3, pode-se afirmar que o CPC 12 (Ajuste a Valor Presente), seguido do CPC 01 (Redução a Valor Recuperável de Ativos), foram os que mais trouxeram modificações relevantes para o ensino da disciplina de Teoria da Contabilidade após o processo de convergências às normas internacionais de contabilidade.

Ao realizar o teste da entropia de informações para grupo de questões da Tabela 3, foi apurada uma média de 0,10. Não houve nenhuma questão que apresentou peso informacional igual à média da entropia.

As afirmações sobre os CPCs 01, 04 e 12 apresentaram peso informacional abaixo da média da entropia, além de média elevada em relação às respostas obtidas. Portanto, pode-se afirmar que há consenso entre os respondentes sobre as modificações que estes Pronunciamentos trouxeram para a disciplina de Teoria da Contabilidade.

Apenas o peso informacional do CPC 00 apresentou-se acima da média, exibindo forte variação nas respostas dos entrevistados, sobre a concordância de que este Pronunciamento trouxe modificações significativas para a disciplina Teoria da Contabilidade.

Ao comparar os resultados do presente estudo com a pesquisa de Cunha, Guidini e Klann (2017), que identificaram a percepção dos professores dos Programas de Pós-Graduação Stricto Sensu em Ciências Contábeis (PPGCCs) do Brasil sobre a abordagem da disciplina Teoria da Contabilidade no cenário da convergência às Normas Internacionais de Contabilidade. E trouxe como os resultados, que quanto aos conteúdos mais enfatizados pelos professores foram o ativo e sua mensuração, o passivo e sua mensuração, receitas, despesas, ganhos e perdas e patrimônio líquido. Com exceção do passivo, os demais achados concordam com o presente estudo, que enfatizou que houve alterações significativas no ensino em Teoria da Contabilidade, advindas do processo de convergência das normas internacionais de contabilidade.

\section{CONSIDERAÇÕES FINAIS}

Este estudo objetivou verificar as principais mudanças ocorridas no ensino da disciplina de Teoria da Contabilidade no Brasil após o processo de convergência contábil internacional, com base na perspectiva dos docentes do Estado do Paraná. Pesquisa descritiva, por meio de levantamento, com abordagem quantitativa, foi desenvolvida para tal. A delimitação deste estudo abrangeu 84 instituições de ensino superior, representando o total de instituições que oferecem o Curso de Ciências Contábeis no Estado do Paraná. Obteve-se uma amostra de 30 docentes da disciplina de Teoria da Contabilidade dessas instituições. Foi utilizado um questionário, dividido em dois blocos, totalizando 26 questões em Escala Likert de cinco pontos.

Quanto às modificações na composição das contas Patrimoniais e de Resultado, observou-se que os docentes concordaram significativamente que houve modificação ao transmitir o conceito de ativo aos alunos por causa da convergência das normas internacionais de contabilidade. Diversas mudanças 
nas contas patrimoniais influenciaram a forma de transmitir o conceito de ativo. A criação do grupo de contas Ativo Intangível, que até então era inexistente, teve forte contribuição, pois surgiram novas interpretações para classificar esse tipo de ativo da entidade.

Os pesquisados concordaram que o termo Goodwill, por exemplo, resultou em dificuldades para trabalhar na prática docente, devido sua origem de difícil definição. A criação do ajuste ao valor recuperável dos ativos, ou teste de impairment, foi um novo conceito que o docente teve que tomar conhecimento e se adaptar para transmiti-lo ao aluno. Outros conceitos que já existiam e sofreram modificações em suas regras de contabilização, como o leasing e a depreciação, também são fatores que os docentes consideram que provocaram modificações ao transmitir o conceito de ativo aos acadêmicos.

Quanto às alterações no conceito de passivo, os pesquisados discordam que houve necessidade de alteração na forma de transmissão ao aluno. Isso se justifica por ter sido um grupo de contas que, no processo de convergência internacional contábil, não passou por tantas alterações quanto o Ativo.

Referente às contas de resultado, os docentes pesquisados concordaram que houve necessidade de alterar a forma de transmitir o conteúdo aos alunos, pois ocorreram modificações nas contas de Receita e Despesa, principalmente no que diz respeito ao ganho e perda.

Sobre a utilização dos Pronunciamentos Técnicos do CPC, como suporte para o docente transmitir as alterações causadas pelo processo de convergência, contatou-se que os respondentes concordam que alguns dos pronunciamentos estão sendo eficazes para aplicação do conteúdo. O teste da entropia demonstrou alta concordância dos docentes sobre a utilização deste instrumento nas aulas, mas sobre sua eficácia para aplicação do conteúdo aos alunos, a concordância foi menor. Pode-se destacar que o CPC 12 (Ajuste a Valor Presente) e o CPC 01 (Redução ao Valor Recuperável de Ativos) tiveram forte destaque na pesquisa como auxílio ao docente para transmitir o conteúdo proposto para os acadêmicos, trazendo modificações relevantes ao conteúdo da disciplina.

Outro ponto a ser destacado é que o Pronunciamento Conceitual Básico (CPC 00) trouxe modificações importantes para às normas de contabilidade do Brasil, embora não tenha sido compreendido como tal por alguns dos respondentes. Dentre as modificações pode-se destacar a alteração dos postulados, princípios e convenções, que passaram a ser tratados como características qualitativas da informação contábil. Além disso, conceitos importantes foram modificados, como o princípio do conservadorismo, substituído pela neutralidade. Essas importantes mudanças não foram observadas por alguns respondentes, o que se verifica na média $(3,7)$ apresentada na Tabela 3. Conclui-se que nem todos os professores podem estar cientes das importantes alterações trazidas por este Pronunciamento (CPC 00).

De acordo com os resultados expressos nesta pesquisa, pode-se concluir que $\mathrm{o}$ processo de convergência às normas internacionais de contabilidade causou alterações no ensino da disciplina de Teoria da Contabilidade, sob a ótica dos docentes do Estado do Paraná. Estes concordam que tiveram que se 
readequar para transmitir o conteúdo dessa disciplina aos alunos e que os pronunciamentos do CPC estão sendo um instrumento de importante utilidade para essa readequação, ao trazer modificações relevantes ao conteúdo da disciplina de Teoria da Contabilidade.

Como sugestão para novas pesquisas relacionadas a este contexto, seria interessante realizar novos estudos abrangendo outras disciplinas, além da disciplina de Teoria da Contabilidade, o que poderia contribuir para a compreensão dos efeitos da convergência das normas internacionais de contabilidade na qualidade do ensino da contabilidade no Brasil.

\section{REFERÊNCIAS}

ALVES, C. S.; BEHR, A.; RAIMUNDINI, S. L. Mensuração e Evidenciação de Ativos Intangíveis em Demonstrações Contábeis: O Estudo de Caso em um Clube de Futebol Brasileiro. Revista Catarinense da Ciência Contábil, v. 11, n. 32, p. p. 0925, 2012.

ANTUNES, M. T. P.; GRECCO, M. C. P., FORMIGONI, H. A adoção no Brasil das normas internacionais de contabilidade IFRS: o processo e seus impactos na qualidade da informação contábil. Revista de Economia e Relações Internacionais. V. 10, n²0, p. 5-19, 2012.

BARBOSA, J. E. N.; DIAS, W. O; PINHEIRO, L. E. T. Impacto da Convergência para as IFRS na Análise Financeira: um estudo em empresas brasileiras de capital aberto. Revista Contabilidade Vista \& Revista, Belo Horizonte, v. 20, n. 4, p. 131 $153,2009$.

BORBA, J. A.; POETA, F. Z.; VICENTE, E. F. R. Teoria da contabilidade: uma análise da disciplina nos programas de mestrado brasileiros. Sociedade, Contabilidade e Gestão. v. 6. ก. 2, 2011.

BRASIL. Lei $n^{\circ}$ 6.404, de 15 de dezembro de 1976. Dispõe sobre as Sociedades por Ações. Disponível em:

<http://www.planalto.gov.br/ccivil_03/leis/l6404consol.htm> Acesso em 09 maio 2013.

BRASIL. Lei n $n^{\circ} 11.638$, de 28 de dezembro de 2007. Altera e revoga dispositivos da Lei $n^{\circ}$ 6.404, e da Lei $n^{\circ} 6.385$, e estende às sociedades de grande porte disposições relativas à elaboração e divulgação de demonstrações financeiras. Disponível em: < http://www.planalto.gov.br/ccivil_03/_ato2007-

2010/2007/lei/l1 1638.htm> Acesso em: 09 maio 2013.

CFC, Conselho Federal de Contabilidade. Resolução CFC $n^{\circ} \mathbf{1 . 0 5 5 / 0 5}$. Cria o Comitê de Pronunciamentos Contábeis - (CPC), e dá outras providências. 2005. Disponível em:

<http://www.cfc.org.br/sisweb/sre/detalhes_sre.aspx?Codigo=2005/001055>. Ac esso em: 08 maio, 2013. 
COMITE DE PRONUNCIAMENTOS CONTÁBEIS. Disponível em: <http://www.cpc.org.br/pronunciamentosIndex.php>. Acesso em: 08 maio 2013.

COMITÊ DE PRONUNCIAMENTOS CONTÁBEIS. Disponível em: $<$ http://www.cpc.org.br/pronunciamentosindex.php>. Acesso em: 26 março 2018.

CUNHA, L. C.; GUIDINI, A.; KLANN, R. C. A Disciplina de Teoria da Contabilidade e a Convergência às Normas Internacionais de Contabilidade: Percepção dos Professores dos Programas de Pós-Graduação Stricto Sensu em Contabilidade. Pensar Contábil, v. 19, n. 68, p. 4-16, 2017.

DANTAS, J. A.; NIYAMA, J. K.; RODRIGUES, F. F.; MENDES, P. C. M. Normatização Contábil baseada em princípios ou regras? Benefícios, custos, oportunidades e risco. Revista de Contabilidade e Organizações. v. 4, n. 9, p. 3-29, 2010.

DING, Y.; HOPE, O. K.; JEANJEAN, T.; STOLOWY, H. Differences between domestic accounting standards and IAS: measurement, determinants and implications. Journal of Accounting and Public Policy. v. 26, p. 1-38, 2007.

ELBANNAN, M. A. Accounting and stock market effects of international accounting standards adoption in an emerging economy. Review of Quantitative Finance and Accounting. v. 36, n. 2, p. 207-245, 2011.

ESPEJO, M. M. S. B.; CRUZ, A. P. C.; COSTA, F.; ESPEJO, R. A.; COMUNELO, A. L. Evidências empíricas do ensino no curso de ciências contábeis - uma análise das respostas às alterações provenientes da Lei 11.638/07. Revista de

Contabilidade do Mestrado em Ciências Contábeis da UERJ. v. 12, n. 1, p. 22-39, 2010.

ESPERANTO, C. Consagração do IFRS como norma contábil universal obrigará o Brasil a unificar seus dialetos. Razão Contábil, ano 4, n. 38, p. 36-40, jun. 2007.

FAHL, A. C.; MANHANI, L. P. S. As perspectivas do profissional contábil e o ensino da contabilidade. Revista de Ciências Gerenciais. v. 10, n. 12, 2006.

FERNANDES, B. V. R.; LIMA, D. H. S.; VIEIRA, E. T.; NIYAMA, J. K. Investigação Empírica da Percepção dos Docentes dos Cursos de Graduação em Ciências Contábeis sobre a Função e Atuação do Comitê de Pronunciamentos Contábeis. In: $10^{\circ}$ CONGRESSO USP DE CONTROLADORIA E CONTABILIDADE. Anais... São Paulo, 2010.

FERREIRA, A. F.; SPLITTER, K.; BORBA, J. A.; VICENTE, E. F. R. Teoria da Contabilidade: Uma disciplina específica ou conhecimentos que deveriam estar integrados em outras disciplinas? Revista Brasileira de Contabilidade, n. 202, p. 30-43, 2013.

HENDRIKSEN, E. S.; BREDA, M. F. V. Teoria da contabilidade, tradução de Antonio Zoratto SANVICENTE. São Paulo: Atlas, 1999. 
HERNANDES, D. C. R.; PELEIAS, I. R.; BARBALHO, V. F. O Professor de Contabilidade: habilidade e competências. In: PELEIAS, Ivam Ricardo (Org.).

Didática do Ensino da Contabilidade - Aplicável a outros Cursos Superiores. São Paulo: Saraiva, 2006. p. 61-119.

IUDICIBUS, S. Teoria da Contabilidade: Evolução e Tendências. Revista de Contabilidade do Mestrado em Ciências Contábeis da UERJ. v. 17, n. 2, p. 8-13, 2012.

IUDICIBUS, S.; MARTINS, E.; CARVALHO, L. N. Contabilidade: aspectos relevantes da epopéia de sua evolução. Revista Contabilidade \& Finanças, v. 16, n. 38, p. 719, 2005.

IUDÍCIBUS, S.; BEUREN, I. M.; SANTOS, V. D. Ensino da Teoria da Contabilidade nos Programas de Pós-graduação de Ciências Contábeis do Brasil. Revista Universo Contábil, v. 12, n. 4, p. 6-29, 2016.

LIMA FILHO, R. N.; BRUNI, A. L. Percepção dos Graduandos em Ciências Contábeis de Salvador (BA) Sobre os Conceitos Relevantes da Teoria da Contabilidade. Revista de Educação e Pesquisa em Contabilidade (REPeC), v. 6 , n. 2, p. 187-203, 2012.

MADEIRA, G. J.; MENDONÇA, K. F. C.; ABREU, S. M. A disciplina teoria da contabilidade nos exames de suficiência e provão. Revista Contabilidade Vista \& Revista. Belo Horizonte, ed. Especial, p. 103-122, 2003.

MARION, J. C. A Disciplina Teoria da Contabilidade nos Cursos de Graduação Algumas Considerações. Contabilidade Vista \& Revista, v. 8, n. 2, p. 03-08, 1997.

MARTINS, Gilberto de Andrade. THÉOPHILO, Carlos Renato. Metodologia da investigação para ciências sociais e aplicadas. São Paulo: Atlas, 2007.

MINISTÉRIO DA EDUCAÇÃO (MEC). Disponível em: http://emec.mec.gov.br/. Acesso em Jul. 2013.

NIYAMA, Jorge Katsumi. Contabilidade internacional. 1. ed. 4. reimpr. São Paulo: Atlas, 2007.

PICCOLI, M. R.; CHIARELLO, T. C.; KLANN, R. C. A percepção dos acadêmicos sobre conceitos abordados na disciplina de teoria da contabilidade. Revista de Gestão, Finanças e Contabilidade, v. 5, n. 1, p. 40-57, 2015.

ROCHA, Irani. Grau de entropia da informação em indicadores econômicofinanceiros das empresas que participam dos níveis de governança corporativa da BM\&FBovespa. 2010. 155 f. Dissertação (Mestrado em Ciências Contábeis) Programa de Pós-Graduação em Ciências Contábeis da Universidade Regional de Blumenau, Blumenau, 2010.

RODRIGUES, M. M. J.; ZONATTO, V. C. S.; LAVARDA, C. E. F. Participação dos diferentes departamentos e unidades no sistema orçamentário: um estudo de 
caso em uma Instituição de Ensino Superior do Estado de Santa Catarina.

Contexto, v. 12, p. 27-41, 2012.

ROSA, F. S. ; SOARES, S. V. ; ROSA, V. S. ; LUNKES, R. J. ; PFITSCHER, E. D. . A Identidade da Teoria da Contabilidade: uma Análise de Aspectos da Legitimidade Sócio-Política e Cognitiva da Disciplina no Brasil. Revista Electrónica Iberoamericana Sobre Calidad, Eficacia y Cambio en Educación, v. 10, p. 239263, 2012.

SACRAMENTO, C. O. J. O ensino de teoria da contabilidade no Brasil. Caderno de Estudos Fipecafi, São Paulo, v. 10, n. 18, p. 01-10, 1998.

SANTOS, J. L.; SCHIMIDT, P; PINHEIRO, P. R.; FERNANDES, L. A. Estudo comparativo do tratamento contábil dos prejuízos não realizados intercompanhias na consolidação nas normas brasileiras, internacionais e nos US-GAAP. Revista Brasileira de Contabilidade, Brasília, n. 183, p. 95-109, 2010.

SOARES, S. V.; SILVA, G. R.; PFITSCHER, E. D. Teoria da Contabilidade: O que se ensina nos cursos de Ciências Contábeis das Universidades Federais

Brasileiras?. Revista de Contabilidade da UFBA, v. 5, n. 3, p. 45-57, 2011.

SOARES, S. V.; VICENTE, E. F. R. Bibliografia brasileira sobre Teoria da Contabilidade: o que se encontra nos livros? Práticas em Contabilidade e Gestão, v. 2, p. 31-61, 2014.

SOUZA, F. F.; VICENTE, E. F. R. Compreensão dos Graduandos dos Cursos de Ciências Contábeis Quanto aos Conceitos Relevantes Ensinados na Disciplina de Teoria da Contabilidade em IES da Grande Florianópolis . Revista de Educação e Pesquisa em Contabilidade, v. 11, n. 1, p. 110-126, 2017.

THEÓPHILO, C. R.; SACRAMENTO, C. O. J; NEVES, I F.; SOUZA, P. L. O ensino da teoria da contabilidade no Brasil. Contabilidade Vista \& Revista. Belo Horizonte, v. 11, n. 3, p. 3-10, dez. 2000.

ZELIOLI, R. J. Análise de cenários para adequações as Normas Internacionais de Contabilidade (IFRS). Anuário da Produção de Iniciação Científica Discente, v. 12, n. 13, p. 183-193, 2009. 